\title{
ORIGIN OF THE BAKEVELLIIDAE, EVOLUTION OF THE MULTIVINCULAR LIGAMENT AND IMPLICATIONS FOR THE MESOZOIC BIVALVE RADIATION
}

HEANEY*, Michael J., III, Department of Geology, Texas A\&M University, College Station, TX 77843-3115, U.S.A.; YANCEY, Thomas E., Department of Geology, Texas A\&M University, College Station TX 77843-3115, U.S.A.

The Buckhorn Asphalt (Desmoinsean, Pennsylvanian) of south-central Oklahoma has yielded a diverse and exquisitely preserved, shallow marine Molluscan fauna, including many minute taxa. This window into the shallow marine biota of the late Carboniferous, provides insight regarding evolutionary relationships of several molluscan clades and the Mesozoic Bivalve radiation. It confirms a Pterineidae ancestry for the Bakevelliidae, and allows documentation of crucial character states such as: shell microstructure, ligament ultrastructure, geochemical composition, prodissoconch 1 and 2 stages, as well as hinge dentition and ligament details for members of both families. Three previously undescribed species of pterioid bivalve, provide new data on this clade. These forms include: 1) a pterineid closely related to Leptodesma, with an alivincular ligament type, 2) the earliest known bakevelliid, possessing a rudimentary multivincular ligament, and 3) a transitional form which has but one shallow ligamental pit located beneath the beaks. These ancestral forms consist of minute species that develop character states used as family defining features in the Mesozoic. This study extends the range of the predominantly Mesozoic bakevelliids, and documents the early evolutionary development of the ligament type which characterizes the group.

Additionally, these taxa demonstrate the Carboniferous origin of the Mesozoic bivalve radiation, and provide invaluble data concerning the roots of the radiation prior to the firm establishment of Mesozoic clades. The key family defining character was established in the Carboniferous yet did not come to fruition until the Mesozoic. These taxa also enable one to establish multiple working hypotheses regarding the functional and adaptive significance of this ligament type. The multivincular ligament may: 1) conserve constructional material, 2) facilitate a more endobyssate life position, or 3) simply be a neutral character of little or no adaptive value. The exceptional preservation of the Buckhorn Asphalt biota provides a unique opportunity to evaluate such evolutionary and paleoecological relationships. 